\title{
22 Crime and fear in public places
}

\author{
A global look
}

\author{
Mahesh K. Nalla and \\ Vania Ceccato
}

\subsection{Introduction}

This volume brings together a collection of original research that addresses the fear of crime and safety with a focus on public places such as parks, green spaces and public transit, from scholars from around the world. These original contributions highlight and demonstrate fear of crime and safety concerns intersecting with spatial and geographic locations. This volume adds to the growing literature on underscoring the significance of fear of crime as an integral part of social and geographic concerns centered on environmental planning and urban affairs. Scholars from both developed and emerging democracies have contributed to this volume, covering a wide range of countries from the global North and the global South. They include Brazil, India, Japan, Mexico, Nigeria, Pakistan, Poland, Sweden, the United Kingdom and the United States. The comparative research presented in this edited volume has focused both on theoretical and methodological issues, with practical and pragmatic recommendations for policy. In this chapter, we synthesize and critically review some of the key findings based on each chapter and subsequently on the five crosssectional themes. We identify relevant lessons and challenges that emerge from a variety of research fields and country contexts.

This book is divided into seven parts. The first part consists of three chapters that lay the theoretical and conceptual frameworks for the various original research papers selected for inclusion in this volume. The first chapter introduces crime and fear in public places and defines the scope and theoretical framework of the book. In Chapter 2, Ceccato provides an overview of the theories surrounding the circumstances of crime and fear of crime in public spaces. She begins with the description of the concept of public places in relation to the dynamics of urban crime and fear and identifies competing theories that identify the mechanisms that link crime and fear with the built environment, and finally analyzes the role of architects, planners and safety experts in the implementation of safety interventions in planning practices.

In the final article in this section (Chapter 3), Ceccato provides a comprehensive literature review on the architecture of crime and fear of crime drawing evidence in the international literature on the relationship between various 
crime prevention strategies such as surveillance cameras, lighting, and other guardianship attributes and their impact on individual' perceptions of safety and fear of crime. In this chapter, Ceccato reviews a massive amount of literature published between 1968 and 2018, drawn from various databases including Scopus, Web of Science, and JSTOR. More specifically, the literature review covers three issues: the impact of urban design on crime and fear of crime; the effect of lighting and/or surveillance on crime and perceptions of safety; and, by focusing on the creation of barriers and gated communities, the author discusses the impact of the "side effects" of prioritizing this type of "safety solution" on the overall city sustainability. The author concludes by answering the following question: what makes a public place safe? Lighting and maintenance are for sure important components of a safe public place but these characteristics, she concludes, often do not come alone. An environment that promotes guardianship also makes it safe, and seems to be a recurrent aspect of these studies. People's involvement in local (crime preventive) initiatives may also help curb crime and improve safety. A note of caution is necessary because although the sample covers more than 4,000 articles, it is biased towards expected positive results. This means it is impossible to know how many studies that have produced negative or "unexpected" results were never published. The author recommends caution with these results also because not all technical solutions that positively affect crime, can produce sustainable outcomes (for instance, gated communities).

\subsection{The environment}

The second section, entitled The environment, highlights crime and perceptions of the safety of urban spaces with specific reference to parks and designated green spaces, which are the landscapes of urban planning. Two articles focus on open urban spaces, more specifically parks and green areas located in urban settings, which while designed for residents and visitors to relax and spend quality time with families and friends are also contested spaces and that perceptions of safety and crime are strongly tied to residents' decision to use these spaces. The third article in this section focuses on public spaces such as school premises as avenues for specific forms of victimization, particularly disability hate crimes. In the first article of the section (Chapter 4), Ceccato and her colleagues conduct a comprehensive review of the literature on the relationship between green spaces in cities and their impact on citizens' perceptions of crime and safety. Drawing from existing research on the subject matter and placing it in the context of research from other parts of the world, authors reviewed nearly 5,000 research articles from the past five decades to systematize scholarly knowledge on the topic. A majority of the articles ( 60 percent) of the studies were based in the US, 23 percent from Europe, and 23 percent from Asia. More specifically, they summarize findings from prior research that addresses the common types of green areas (i.e., parks, green areas in neighborhoods, and woodlands) associated with risk of crime and perceived safety, if green spaces 
are related to the incidence of crime and disorder, and, finally, the ways in which green spaces shape perceptions of safety and fear of crime among the citizens. Based on this extensive review the authors cautiously conclude that there appears to be evidence for green areas in cities having a positive impact on decreasing crime. The authors' cautionary tale stems from a lack of fairly extensive literature that covers a wide range and variety of green areas in cities. Second, given a wide range of methods employed to examine these issues, drawing comparisons from these the results can be complicated. Finally, the authors also caution the applicability of findings from mostly North American and the United Kingdom to emerging democracies and the areas in the global south.

The findings of a positive relationship between green areas and perceived safety have implications for policy. Given that green spaces are often contested spaces in a city, the authors highlight that plans to create green areas is essentially a plan for safer cities and inclusivity for all groups of residents in the community. This process requires multifaceted approaches and continued commitment from multiple authors.

The next article (Chapter 5 ) focuses on safety within urban parks and the fear of crime in general in parks. Bogacka, drawing from a case study in Cytadela Park in Poznań, Poland, examines the specific characteristics of a park that makes users feel safe and the extent to which perceptions of safety are impacted by the physical and social environments of the park. The park includes playgrounds, fortifications, museums, cemeteries, monuments, sculptures, an amphitheater, two restaurants, and two open-air gyms. Drawing from the conceptual framework of Crime Prevention Through Environmental Design (CPTED) and a survey of over 500 users about crime risk, Bogacka measures the quality of the environment of the park and how that relates to its safety. More specifically, employing the six CPTED concepts of territoriality, surveillance, access control, target hardening, the image of the place/maintenance and activity support this research evaluates the safety within urban parks as well. Considering the size of the park and its location in the city and situated in the residential area, the park receives a lot of human traffic from both domestic visitors and tourists. Findings from this study reveal that most of the users walk alone in the park or engage in physical exercise activities. Park users feel safer during the day in contrast to at night. Additionally, regardless of the time of day, older visitors to the park felt less safe. Park users identified adequate lighting, the presence of another person or people, video surveillance, and the presence of the police as factors associated with the feeling of safety. Findings also suggest that alcohol consumption, the presence of homeless people and vandalism were among the key factors resulting in park users' sense of perceived fear of park usage. Drawing from these findings, the author suggests some pragmatic recommendations for improving a sense of safety and reducing fear of victimization that include the organization of more social events, renovating the amphitheater, adding benches, placing garbage bins and improved lighting. 
The third article in this section (Chapter 6) is a comprehensive literature review that focuses on disability hate crimes (DHCs). More specifically, the goals of Girolimetto and Iudici were to ascertain where such crimes are more likely to occur, how different locations facilitate this form of crime and to offer suggestions of how public places may limit violence and DHCs, a form of crime that is under-reported relative to other types of crime. Drawing from a large number of studies on the subject and identified in databases of Scopus and PubMed, the authors identify the role of public places' in aiding the occurrence of DHCs. They limited their research to printed articles, reviews, notes, and editorials and searched using the main keyword 'disability hate crime' and present their findings in three categories: locations where DHCs were most likely to occur; public places as an active factor in aiding DHC events; and, public places as an active factor in preventing DHC events.

School environments, public spaces along with streets, and government buildings are primary locations of DHC incidents. They identify disabled children as most vulnerable to DHC violence which occurs in institutions and communities and state that many disabled people live in isolation in vulnerable conditions. For the second category that relates to how specific locations facilitate DHC events, the authors found three factors contribute to DHC occurrences: poverty and deprivation and spaces that often have limited guardianship, such as public institutions and virtual spaces. Lastly, the authors find from prior research that suggests that changes in the structural conditions of public places may help to limit violence, harassment, abuse, and crime. While this literature review focused on education and virtual environments, the authors find that addressing negative attitudes towards disabled people can help to make an educational environment a safe place. This literature review also revealed support for virtual forms of communication as a medium to implement diagnostic prevention systems to identify forms of hate.

\subsection{The movement}

The focus of this section is on perceptions of safety and victimization in public transit. Contributions for this section come mostly from the global South. The essence of these contributions is that public transit, as part of the urban space that facilitates movement for urban residents, can be prime sources of crime, sexual violence and victimization, which degrade the quality of urban life for its residents. Despite the diversity of geographic locations that served as the research settings, common threads among the findings are evident. Gender, time and frequency of commuting are all associated with a higher degree of sexual victimization and sexual harassment. Additionally, these research articles highlight the issues regarding the safety of public transportation and ways to reduce these problems with a focus on increasing guardianship through both physical and electronic monitoring systems, mechanisms identified in the literature on situational crime prevention (SCP) and CPTED. The underlying theme is that understanding the logistics of sexual victimization in public transportation 
would help generate ideas to make it easier to solve the specific issues in particular locations.

The first of the four studies (Chapter 7) by Romero-Torres and Ceccato address the issue of sexual harassment and safety perceptions of public transportation users in the eastern part of Mexico City, Mexico. The authors surveyed 381 university students from the CU Nezahualcóyotl campus to assess their perceptions of safety and victimization from three forms of sexual offenses, which were nonverbal sexual violence/abuse, verbal sexual violence/abuse, and physical sexual violence/abuse. The findings suggest that compared with men, more women reported sexual victimization of one form or another. The likelihood of victimization occurs most often in buses followed by Metros. The findings also reveal that both frequency and duration, as well as the time of the day, are strongly linked to victimization. That is, the longer the duration of travel and the greater the frequency of commuting, the higher the likelihood of victimization occurring. Among the forms of sexual victimization, more victims experienced verbal victimization in buses and non-verbal victimization was more common in the Metros.

Other interesting observations from the victims reveal that the offender's anonymity at times in these areas makes it easier for these types of crimes to occur. In particular, in the absence of a capable guardian-that is, if offenders do not believe they are being watched by either other people or technologythey are more likely to commit a crime. The study also highlights four main categories of behavioral responses to the fear of crime: avoidance behavior, protective behavior, behavioral and lifestyle adjustments, and participation in relevant collective activities. Findings from this study prompt the authors to recommend constant monitoring of areas surrounding public transportation, including public transit while on board.

The second study in this section (Chapter 8 ) focuses on public safety perceptions among college students in Tokyo/Kanagawa public transit systems in Japan. In this study, Shibata examines women's perceptions of how safe they feel commuting in these railway cars. The main concern the women experience in this study is sexual offenses focused on groping while traveling by trains, and other forms of sexual violence in transit environments. Findings from a survey of 400 college students comprising both males and females reveal gender differences in sexual victimization, that is, females are the predominant victims of various forms of sexual harassment. Among the various forms of sexual harassment, groping was the most common form of violence experienced by women commuters. The researchers also discuss two countermeasures against groping: women-only cars and CCTV cameras as security measures on trains and platforms.

The next article (Chapter 9) centers on university students' perceptions of safety and experiences of gender violence and crime in public transit, which included bus stations and on-board buses in the Brazilian city of Rio Claro. Three forms of violence were included in this study: sexual assault or harassment; other forms of violent crime (aggravated assault, robbery, rape); and, 


\section{4}

property crime (theft/pickpocket, jewelry snatching or robbery). The data collected from 569 students included nearly 18 percent who identified themselves as Lesbian, Gay, bisexual, and transgender (LGBT). As in the previous research findings from Mexico and Japan highlighted in this section, women in Rio Claro, Brazil, were more likely to be victims of all forms of crime including sexual violence and harassment. Perhaps, a more interesting finding from this study was that female LGBTs were five times or more likely than male LGBTs to be victims of sexual assault and harassment. Apart from the high degree of victimization of crime and sexual violence, 95 percent of all those surveyed feared using the bus service at night-time and 70 percent during daytime, with nearly two-thirds of all respondents identifying sexual assault or harassment as the main form of fear.

Drawing from these results, the researchers identified five measures that best contribute to improving safety in public transportation. These include better lighting, police patrol, surveillance cameras on board the bus and at bus stops, and digital timetables at bus stops. The authors also suggest that improving public knowledge through campaigns and educational programs, though a long-range goal, will help sensitize and bring and raise awareness among users of public transportation. The authors also acknowledge that some of these changes are easier or more attainable than others, such as better lighting and cameras, while police patrol and educational programs are more difficult. Additionally, having more patrols around bus stops and relocating bus stops to safer places requires more organizing and planning than may seem.

Common themes and findings also emerge from research (Chapter 10) from Lagos, Nigeria. Otu and Agugua examined perceptions of fear and actual crime in public transport systems (PTS) and networks. While PTS constitutes the most common forms available for transportation in the high-density population of Lagos, the limited availability of PTS relative to the demand results in overcrowding of these stations and, consequently, crime. Similar to the research reported earlier in this section, compared with men, women report in greater numbers both the fear of crime and criminal victimization in PTS, the most common forms being pickpocketing, robbery and sexual harassment. This study identifies several recommendations for safety improvements, including surveillance cameras, digital timetables, direct police lines and more police officers, improved lighting, and women-only modes of transportation. As with many public transport safety issues, while recommendations such as additional lighting, use of cameras and digital timetables are more attainable solutions, calls for more police officers and womenonly modes of transportation are harder to attain.

\subsection{The users' perspective}

The articles in this section, The user's perspective, address both conceptual arguments relating to contested spaces, both in terms of individual and spatial dimensions as well as perspectives from the victims, and one article in particular 
from the offenders' perspectives. In the first article in this section (Chapter 11) Vera-Gray and Kelly discuss the issues regarding women's safety in public spaces. The feminist movement has been seen throughout history and is constantly changing, along with the safety issues that females face in public spaces. The issue with studying this area of crime is understanding the right to public spaces and trying to gender the fear of crime. It is hard to understand why women report significantly higher levels of fear of crime than men, but women have a lower rate of victimization and Vera-Grey and Kelly explain why gendering fear of crime is complex. According to the authors, studies of gender and work have brought about two forms of invisible work for women: violence work and safety work. Violence work is the work women must do to undo the harms and make their lives livable, which takes time and energy that could have been spent on more meaningful projects. On the other hand, safety work is work that women do to avoid violence in public space. What we draw from this research is an understanding of, and an increase in our knowledge of, the strategies women and girls adopt and adapt to avoid potential threats. These strategies include altering routes going to and from home, and making strategic choices of seating on public transport, physically minimizing their presence in public, with headphones and sunglasses usage to make themselves more invisible, all to avoid sexual harassment and other forms of sexual violence. The authors propose that future research should investigate public places where women feel they must practice the most safety work. Understanding these public situations and places will help to better understand how to make them safer for not only women but all who come into contact with these spaces. It is also important to understand why these public spaces are contested gender spaces. There may be an issue that is not as apparent as researchers may think that could be causing women to feel like they need to practice either type of invisible work.

A slight departure from the research reported here, which predominantly focuses on victims, can be found in the next article (Chapter 12) by Nalla, which captures sexual harassment and sexual violence experiences from the perspectives of both the victims and the offenders. Drawing data from a large sample of nearly 1,400 male and female respondents, using multistage cluster and quota sampling, who travel by public transport in New Delhi, India, Nalla examined the incidence of victimization and the age distributions of both victims and offenders on a range of sexual harassment $(\mathrm{SH})$ experiences. In addition, he also examined male offenders' self-reported offending patterns, male offenders' friends offending, as well as the awareness of the existence of laws relating to sexual harassment and their effectiveness. Compared with other research in this section, which focused exclusively on the college-going population, this study included the general population. Findings suggest that victims and perpetrators of sexual harassment ranged across all age categories. A higher concentration of victimization rates was found in the age groups of 18 to 40 years, although there was a considerable concentration of victims in the age group of 41 and 80 years. A similar distribution of offending patterns among 
males was also observed, with nearly a third under the age of 30 years and about 16 percent of all offenders in the age group of 51 years and stretching into their 70s. Perhaps, an important result from this study is the finding of a high congruence between self-reported offenders and knowing a male friend who has engaged in similar sexual harassment behaviors, suggesting the perpetration of these behaviors occurs in the company of friends. Additionally, although less than half of the offenders (42.2 percent) knew there were punishments associated with $\mathrm{SH}$ offending, less than a third believed that the SH laws (29.2 percent) or SH enforcement of laws (33.8 percent) were effective. These perceptions may have some impact on their behavior and willingness to engage in $\mathrm{SH}$.

Similar to findings from the study in Lagos, Nigeria, the author raises issues relating to the infrastructure deficiency in relation to public transportation in New Delhi. Given the overcrowding of transport areas, such as bus and metro stations, as well as the public transport system, guardianship and surveillance concerns become paramount. Furthermore, citizens' trust in the legal system or law enforcement is far from positive, giving rise to cynicism as well as the absence of legitimacy in the governance of crime. However, the author suggests the utilization of the sports and entertainment industry idols, who have a large fan following in India, to provide public service messages on this form of social problem.

Unlike the papers summarized earlier, the next paper (Chapter 13), by Stjernborg and Bamzar, focuses on older adults' perceptions of crime. The setting for this study is two neighborhoods, Hässelby Gård and Seved, which are located in the two major cities of Sweden, Stockholm and Malmö, respectively. Approximately 15 percent of Hässelby Gård's and 8 percent of Seved's population are in the age group of 65 and 93 years. These people have unique characteristics that are important to examine when trying to understand how crime and fear of crime affect older adults. Fear of crime in older adults is influenced by many factors, such as marital status and health as well as the significance of loneliness and low levels of life satisfaction. News and media also play a role in the perception of safety. The article explains mental maps being used to express a person's perceptions of different places, including views on where they want to go and places they want to avoid. It is important to look at how the news and media may affect people's perceptions of certain areas, especially those perceptions of older people. The lack of social participation that can come with aging may also lead to a low perception of safety. The study shows that daily life may be affected by the fear of crime. People change their daily activities and schedules because of their perception of crime in the areas they populate. The role of the context of daily life should be further researched to better understand and meet the needs of older adults. Understanding their daily lives will also help to develop age-friendly neighborhoods that allow older people to stick to their daily routines and not have those routines affected by the fear of crime. Additionally, more research should be done regarding social participation and how that plays a significant role in the fear of crime. This area of interest would also benefit from research regarding the roles that municipalities and other actors play in supporting the older generation and "healthy aging". 
The location of the following chapter (Chapter 14) by Yates and Ceccato is also set in Sweden's capital city of Stockholm. This chapter focuses on women's fear of crime, but specifically on how this fear of crime varies. Findings from three large surveys administered in 2008, 2011 and 2018 reveal that women's fear of crime is not homogeneous and is individual. Further, relationship status, ethnic background and gender status also play a major role in fear of crime. A strong relationship between fear of crime and the neighborhood's social and physical characteristics is also established in this research. Women would express more fear in public space than in private space, even though most attacks against women occur in the private space (domestic environment) by people that they know. It is a paradox because women experience more fear in public spaces, which in turn makes them change and adapt to how they move in these spaces. However, they do not change or adapt their behaviors in more domestic spaces because they feel safer, even though they are at greater risk of victimization in these private spaces. As with previous research, reported fear of crime is higher for women than men. A strong factor in high fear of crime among women is poor social connections. Further research in this area would help to better understand women's views on their personal social connections and how to better these so they feel safer in public spaces. The study also shows that young women have a high fear of crime, and research looking at the intersections between age, family structure, and socio-economic status could help to better understand how fear operates in the lives of young women. Additionally, looking at individual and environmental characteristics of where women live and how that relates to crime will help to better understand the fear of crime they may have.

\subsection{The metrics}

This section consists of three research papers that address the measurement of fear of crime using novel methodologies. The first of these papers (Chapter 15), by Irvin-Jackson and Kamiran, considers the factors shaping fear of crime in public transit in Lahore, Pakistan. This chapter employs Ecological Momentary Assessments (EMAs) to collect real-time and near real-time data on an individual's fear of crime among users of public transit. Deploying EMAs through a mobile survey app in Lahore, Pakistan, the authors gathered real-time and near realtime context-specific data on fear of crime. Fear of crime can be dependent on many factors, including different times of transit, different modes of transit, and different stages of travel. Additionally, the perceived level of incivilities and experiences of crowdedness in and around public transit can play into the fear of crime. This study would gain empirical support if it were to have a larger sample group; however, future research may benefit from using EMAs as a way to collect data. Future research would also benefit from looking at these data from the individual level. As other research has shown, the fear of crime is not homogeneous and may change per person. Examining the relationship between the fear of crime and characteristics among individuals can be beneficial in 
understanding how to combat the fear of crime. This research also has relevance to fields that fall outside the realm of criminology. It is important to take the data that have been collected and use them to better understand this area of research. The data can be taken into further research or used to implement policy. Lastly, examining the relationship between fear of crime and transit times, transit modes and stages of travel will help to better understand how the fear of crime may change based on the variations dealing with transit.

The next article (Chapter 16) by Magnusson examines open drug scenes (ODS), which are public places where drug use and distribution are common. These areas are typically located close to transportation hubs and central business districts and are the scene of various types of crime. These drug scenes gain attention and make people fearful of these areas and affect living environments, cause safety issues and create problems for the surrounding neighborhoods and communities. ODS has a negative impact on the communities and causes a perceived fear of crime in those areas. Drug scenes also have a perceived disruption that comes with them. It is important to understand where these drug scenes are most likely to occur to better implement strategies to combat them. The use of police-recorded data and Geographical Information Systems underlie the methodology used in this study. Open drug scenes are most common in areas of transport because drug use and distribution rely on populated areas where they can be hidden. There needs to be additional research in these areas to see the impact of cameras and lighting and understand if those types of strategies are working. Additionally, hot spot policing may also be a method to combat these open drug scenes. There are various studies that use hot spot policing, but hot spot policing in transit areas may need more empirical support and research.

In the last article of this section (Chapter 17), Castro-Toledo and his colleagues examine fear of crime in the realm of cyberspace. They specifically look at the fear of cyberspace through social media and how fear of attacks is spread through the medium of language. Although the fear of crime is difficult to define and measure, the researchers are attempting to encode authors' emotions through Twitter so they can track fear across different "places" and time in cyberspace. They are also specifically looking at tweets regarding terrorism and the emotive profile or response or emotional response that comes from them. The researchers show that the experience of fear through Twitter users is not something that can be documented immediately. They show that this fear in cyberspace can be analyzed and accounted for as if it were measured at the time of their experience. Furthering this type of research would include more realtime data research. This would help to understand the immediate feelings or fear of crime associated with the tweet. Someone may feel fearful after seeing a tweet during a certain time and space and then they could see it again and not feel fearful. It would also be important to understand what it is about the tweet that caused fear of crime, or fear of terrorism more specifically. Additionally, more research regarding criminology and linguistics would be beneficial. Understanding how crime and fear of crime work through different social 
media outlets is helpful in understanding how to combat it through those social media outlets as well.

\subsection{The intervention}

Three articles included in this volume address the assessment of interventions to reduce perceptions of fear of crime and crime itself. The first article, a literature review by Struyf (Chapter 18) addresses the question of the impact of reduced street lighting on crime and fear of crime. As city managers around the world have increasingly focused on reducing street lighting with an eye to minimize pollution and deal with diminishing revenues, the consequences emanating from such bureaucratic decisions have not gone unnoticed. One of the fallouts from such decisions is fear of crime, which Pia Struyf addresses in her research. She examines the effect of reduced street lighting on fear of crime, drawing from quantitative and qualitative scholarly publications in the English language between 1960 and 2019 which examined the impact of street lighting on crime and fear of crime. In this literature review, Struyf also examines the concerns relating to measurement issues and the generalizability of the findings of reduced street lighting on crime. She concludes that the findings from the limited scholarship available on the subject suggest that at best the impact of street lighting on crime has been largely inconclusive, leading her to conclude that reducing or switching off street lighting does not necessarily result in increases in crime, in the way that is mostly presumed. However, the available research is inconclusive and limited, with both studies showing certain limitations in terms of generalizability (but see also the review on lighting reported in Chapter 3). Similar findings were noted on the impact of reduced street lighting on fear of crime; however, reduced street lighting was found to have an effect on fear of physical injuries from tripping, traffic accidents, and the general ability to see the night sky. Based in this review Struyf suggests "the right amount of light", based on a careful assessment of the cost-benefits emanating from the energy savings goal and citizens' physical safety, whether it is crimerelated or from physical injuries. In conclusion, she calls for more analysis with greater attention to specific social and physical environments to advise and guide local governments regarding street lighting regimes.

The focus of Garius, Ward, Teague, and Tseloni in the next article (Chapter 19), which is centered on the United Kingdom, examines if outdoor spaces licensed for holding large gatherings such as music festivals, and other forms of recreational activities in the night-time economy (NTE), create opportunities for crime and sexual victimization. The key driver for many of these behaviors is alcohol. In their study, drawing from data routinely collected by police and environmental criminological theories, Garius and her colleagues evaluate the "Drinkaware Crew" harm-reduction initiative developed by Drinkaware's "Drunken Nights Out" campaign, and examine its relevance and applicability to a music festival, another form of NTE. From their evaluation, the authors conclude that the impact of the "Drinkaware Crew" initiative in NTEs was that in 
one city there was an increase in crime, while the results were inconclusive on recorded crime in the test venue in the second city. They suggest that the finding was rather unexpected and inconsistent with existing literature, which shows that increased guardianship reduces alcohol-related harm, while at the same time it is consistent with literature that crime rate changes may be part of police recording and citizen reporting practices as well as changes in public attitudes. Interestingly, however, they find that "Drinkaware Crew" initiatives can be successfully implemented as harm-reduction services at music festivals, with a perceptible drop in alcohol-related harm for both themselves and others. The lessons we can draw from this work are that social media's presence can enhance visibility, and the effectiveness of the program can be improved by increasing the Festival Crew-topatron ratio. Another lesson that can be drawn from this study is creating a welldefined Drinkaware space at festivals to facilitate on-site training and improving the $\log$ accuracy, validity, and reliability for procedures for data collection.

The chapter on Hollygrove neighborhood in New Orleans by Mihinjac and Saville (Chapter 20) offers an uplifting account of achieved neighborhood improvements from high crime, violence, and fear of crime, after the devastation that Hurricane Katrina brought to this region in 2005. The success of community efforts is related to the empowerment of local neighborhoods to achieve lasting improvements. The case study maps out the journey of neighborhood residents as they "aimed to repair their neighborhood, reduce crime and fear, and build their own capacity to solve future problems-a process of neighborhood activation". The authors draw and offer three key lessons from this case study. First, engaging residents in neighborhood crime prevention activities is predicated on social programming of activities for residents to participate and work together in crime reduction efforts. In Hollygrove, the success of this program came from the core relationships that served as the foundation that rebuilt the social capital and social infrastructure. Second, it is required to support residents' efforts with resources such as funds, police support, and training in crime prevention. These resources were critical in providing muchneeded assurance and confidence building for the residents to actively engage in crime prevention activities. Third, small-scale projects served as a catalyst for long-term action projects yielding big changes over time in Hollygrove, an area that has seen extreme inequality and neighborhood disadvantage.

Chapter 21 focuses on safety and urban planning from a Nordic perspective. Despite increasing safety challenges in many Swedish cities, there is a lack of knowledge about how municipalities work with issues of safety in daily planning practices. Using answers from surveys with planners, Ceccato suggests that municipalities vary greatly in their readiness to deal with issues of crime and safety. Natural surveillance, illumination, and maintenance of the city environments are often considered as important for safety, more so in urban municipalities than in those that are rural. Yet, more than half of planners express a lack of guidance on safety issues. The author concludes that it would be beneficial for the creation of safety guidelines to support the work done by urban planners-a model anchored in research evidence and sensitive to the needs of all individuals. 


\subsection{Concluding remarks}

No matter the size or location of a city, urban crime does not happen randomly in space or time. Even within inner-city areas, the degree of criminality varies as a function of people's routine activity and the types of land use that attract and pull people over the day. Part II of this book shows the role of the city structure (green areas in particular) on victimization and safety perceptions. Parks and other green areas appear to have a positive impact on decreasing crime but there is also evidence that perceptions of users differentiate aspects in these green areas that can be linked to the feeling of safety or lack of it. Lighting and maintenance are also highlighted in this book as important components of a safe public place. Studies show that lighting has a reductive effect on a variety of types of crime, from public disorder to homicides, and on fear of crime. In addition, "an environment that promotes guardianship" seems to be a recurrent aspect associated with less crime and fear. A key component in these studies seems to be the individual's capacity to exercise social control in these environments. Some vulnerable groups are more at risk. Places such as school environments, public spaces along streets, and government buildings are, according to the research reported in this book, the primary locations of incidents against individuals declaring a disability. Poor areas with less social control are also associated with these particular crimes.

Cities are dynamic places. Mobility enables individuals to overcome distance, access spaces and perform activities. However, if people feel unsafe, their mobility is limited. Part III of this book focuses on sexual harassment in transit environments and how these incidents affect the lives of many people, in particular women, causing them to experience stress or even fear in everyday life. Place and time avoidance are recurrent phenomena, no matter whether they travel in Brazil, Nigeria or Japan. Some ways of dealing with the problem must change how individuals are educated and require long-term policies. In the short term, taking the physical environment into consideration can be helpful, such as changing the design of transit vehicles, stops, and systems. Adopting 'a whole journey approach' to safety has also been highlighted as a way to improve safety for travelers from door-to-door. The authors in this book agree that there is not a single initiative that completely addresses unwanted sexual behavior and sexual crimes in transit environments, but more focus on the differences in the safety needs of individuals is desirable. Recognizing the intersectionality of safety (e.g., age, gender, disability) is expected to become more central than it is today in the assessment of the mobility needs of travelers. Changes in the perception of transport operators and other stakeholders towards those who are more targets (of victimization) while in transit is an important long-term goal. A more progressive safety agenda, non-gender neutral and tailored to affect the lives of those who have their mobility impaired is also fundamental. A similar message is also suggested in Part IV of the book, focused on users' perspective of safety. Gender, age, sexual status, disability as well as socio-economic conditions are co-identified as contributing to poor safety. The intersections of 


\section{Mahesh K. Nalla and Vania Ceccato}

these dimensions affect the risk of an individual becoming a victim of crime. The situational conditions are shown also to be relevant for explaining patterns of offending and safety perceptions. Local initiatives that focus on changing the physical and social environment to tackle risks and perceptions are also desirable but may not be enough. In in particular, we echo Vera-Gray and Kelly (Chapter 11): we need to return to earlier feminist efforts to create a right for women to occupy public space on the same terms as men. In many parts of the world, women are still smaller, less visible and yet highly targeted by sexual victimization in public spaces. Women should feel they have a right to the city, that they can belong in public spaces on their terms, rather than "gendered business as usual".

These initiatives (or interventions) require further development of groundbreaking methodologies to best assess safety conditions in public places and later tackle them, which has also been well illustrated in Parts V and VI of this book. These chapters provided examples of new types of real-time data sources (tweets) and technologies, as well as new advances in transportation and ICT that are bound to affect people's safety. The challenges in using geographical information and spatially-related techniques to support research and (safety) planning are not merely linked to the data, theory or tools themselves, but to the way in which they are incorporated in the process of decision-making. One of the key conclusions is that it is more beneficial to establish a ground on which to "build-in" safety in an inclusive way at the beginning of the process of construction of an area, than to try "to fix" safety problems after a public area has become a risky, unsafe place. Not only the police but planners, architects and safety experts have a crucial role to play in the process of making safety. Evidence from this book indicates that there is an urgent need to move from a gender-neutral agenda to policies that adopt a perspective that regards the intersection of gender, age and other individual factors that affect one's safety.

In the next chapter, we draw from all contributions to this volume to propose recommendations on how to respond to crime and fear of crime in public places. Finally, we set out an agenda for research and practice aligned to the UN-Habitat Safer Cities program. 